University of Nebraska - Lincoln

DigitalCommons@University of Nebraska - Lincoln

Faculty Publications: Department of

Entomology

Entomology, Department of

2010

Categorizing the Resistance of Soybean Genotypes to the

Soybean Aphid (Hemiptera: Aphididae)

\author{
L. M. Pierson \\ University of Nebraska-Lincoln \\ Tiffany Heng-Moss \\ University of Nebraska-Lincoln, thengmoss2@unl.edu \\ Thomas E. Hunt \\ University of Nebraska-Lincoln, thunt2@unl.edu \\ J. C. Reese \\ Kansas State University, jreese@ksu.edu
}

Follow this and additional works at: https://digitalcommons.unl.edu/entomologyfacpub

Part of the Entomology Commons

Pierson, L. M.; Heng-Moss, Tiffany; Hunt, Thomas E.; and Reese, J. C., "Categorizing the Resistance of Soybean Genotypes to the Soybean Aphid (Hemiptera: Aphididae)" (2010). Faculty Publications:

Department of Entomology. 272.

https://digitalcommons.unl.edu/entomologyfacpub/272

This Article is brought to you for free and open access by the Entomology, Department of at DigitalCommons@University of Nebraska - Lincoln. It has been accepted for inclusion in Faculty Publications: Department of Entomology by an authorized administrator of DigitalCommons@University of Nebraska - Lincoln. 


\title{
Categorizing the Resistance of Soybean Genotypes to the Soybean Aphid (Hemiptera: Aphididae)
}

\author{
L. M. PIERSON, ${ }^{1}$ T. M. HENG-MOSS, ${ }^{1,2}$ T. E. HUNT, ${ }^{1}$ AND J. C. REESE ${ }^{3}$
}

\begin{abstract}
J. Econ. Entomol. 103(4): 1405-1411 (2010); DOI: 10.1603/EC09324
ABSTRACT We evaluated selected soybean, Glycine max (L.) Merr., genotypes during their reproductive stages for resistance to the soybean aphid, Aphis glycines Matsumura (Hemiptera: Aphididae), under greenhouse conditions and documented the categories of aphid-resistant soybean. Two screening studies were performed to assess the level of resistance to the soybean aphid on six soybean genotypes during the reproductive stages of development. Significant differences in aphid damage ratings were detected among the soybean evaluated in the screening studies. Three genotypes (KS4202, K-1639-2, and K1621) were considered moderately resistant based on the assessed damage ratings. Two of these genotypes (K-1639-2 and KS4202), along with a commercial variety ('Asgrow $2703^{\prime}$ ) were used in a follow-up greenhouse study to test for antibiosis and tolerance. For the antibiosis evaluation, KS4202 had significantly more nymphs than Asgrow 2703 and K-1639-2. In fact, KS4202 had a threefold difference in the number of nymphs compared with Asgrow 2703 (81.8 \pm 14.7 and $26.2 \pm$ 13.9 nymphs, respectively) and a fivefold difference compared with K-1639-2 (15.6 \pm 13.9$)$. Although not significant, Asgrow 2703 had more nymphs than K-1639-2. The lower aphid numbers on infested K-1639-2 plants compared with aphid numbers on Asgrow 2703 and KS4202 plants indicates antibiosis for this genotype. No significant differences in average seed weight, number of seeds per pod, or plant damage were observed between infested and control KS4202 plants; however, significant differences in biomass, total seed weight, number of pods per plant, and number of seeds per plant were detected.
\end{abstract}

KEY WORDS Aphis glycines, host plant resistance, antibiosis, tolerance, Glycine max

Soybean, Glycine $\max$ (L.) Merr., are an important crop in the United States and throughout the world. Since the introduction of the soybean aphid, Aphis glycines Matsumura (Hemiptera: Aphididae), to North America in 2000, it has caused considerable damage and yield loss in soybean crops in $>20$ states in the United States and in several Canadian provinces (Hartman et al. 2001, Alleman et al. 2002, Venette and Ragsdale 2004, Beckendorf et al. 2008). Indirect effects of soybean aphid feeding include virus transmission, such as Soybean mosaic virus, and sooty mold buildup due to honeydew accumulation (Clark and Perry 2002, Domier et al. 2003, Davis et al. 2005). Because of the soybean aphid's potentially devastating effects, several management strategies have been developed, including chemical, biological, and cultural control (Wang and Ba 1998, Wang et al. 2000, Fox et al. 2004, Heimpel et al. 2004, Hill et al. 2004, Rutledge et al. 2004, Wu et al. 2004, Fox et al. 2005, Rutledge and O'Neil 2005, Desneux et al. 2006, Brosius et al. 2007, Kaiser et al. 2007, Chacón et al. 2008, DiFonzo 2008, Wyckhuys et al. 2008).

\footnotetext{
${ }^{1}$ Department of Entomology, 202 Entomology Hall, University of Nebraska-Lincoln, Lincoln, NE 68583-0816.

2 Corresponding author, e-mail: thengmoss2@unl.edu.

${ }^{3}$ Department of Entomology, 123 W. Waters Hall, Kansas State University, Manhattan, KS 66506-4004.
}

Despite the progress made in developing effective management strategies for the soybean aphid, it is still necessary to explore alternative management options to reduce pesticide use. Finding soybean cultivars resistant to the soybean aphid is a viable management alternative.

Several screening studies have been conducted to identify soybean aphid resistant soybean. Hill et al. (2004) first reported resistance to the soybean aphid in the United States in three soybean types: 'Dowling,' 'Jackson,' and PI 71506. Jackson and Dowling, along with their ancestor 'Palmetto' were reported to have strong antibiosis, and PI 71506 was found to possess antixenosis. Jackson and Dowling also both have a single dominant gene for resistance to the soybean aphid (Hill et al. 2006a, Hill et al. 2006b). Of 2,147 soybean accessions originally from China, four were found to be resistant to the soybean aphid: PI 567543C, PI 567597C, PI 567541B, and PI 567598B (Mensah et al. 2005). Diaz-Montano et al. (2006) found resistance in varieties K1639 and 'Pioneer 95B97,' along with several other genotypes. Both antibiosis and antixenosis were found in varieties K1639 and Pioneer 95B97. DiazMontano et al. (2006) reported antixenosis in addition to antibiosis in Jackson, Dowling, and Palmetto. The Ragl gene in Dowling and the Rag gene in Jackson that confer resistance have since broken down in the field (Kim et al. 2008). 
A more recent study evaluated resistance in $\approx 200$ genotypes of soybeans in both field and greenhouse studies using two different soybean aphid biotypes (Illinois and Ohio biotypes). The Ohio biotype was shown to have overcome the resistance found in Jackson and Dowling (Kim et al. 2008, Mian et al. 2008). Nine genotypes were identified as resistant or moderately resistant to the Ohio aphids. PI 243540 showed strong antibiosis and PI 567301B and PI 567324 displayed antixenosis. PI 243540 and PI 567301B were also resistant to the Illinois soybean aphids (Mian et al. 2008). Like Jackson and Dowling, the antibiosis in PI 243540 is controlled by a single dominant gene (Kang et al. 2008). It should be noted that the aforementioned screening studies evaluating resistance to soybean aphid were performed during the seedling stages of the soybean (Hill et al. 2004, Diaz-Montano et al. 2006, Mian et al. 2008).

Although resistant sources have already been identified, a limited number of studies have focused on tolerance. Both antibiosis and antixenosis can impose selection pressures on the arthropod pests, which can lead to biotype development. These biotypes can overcome the resistance genes, causing the eventual loss of antibiosis and/or antixenosis in a resistant genotype (Smith 2005). Tolerance, however, does not impose selection pressure on arthropods and may be the most sustainable category of resistance. Tolerance leads to limited biotype development and the tolerant genes are rarely overcome. Also, tolerant plants can enhance the effects of beneficial arthropods by preventing exposure to the morphological and behavioral effects brought on by antibiosis and antixenosis (Smith 2005). The major disadvantage of tolerance; however, is that if used as a single management tactic, it could lead to large numbers of alate aphids that could subsequently infest nontolerant soybean and/or vector viruses across the landscape.

Although some studies have examined resistance in both the seedling and later vegetative/reproductive stages, the majority of initial screening studies of new germplasm sources have focused on the seedling stage. The soybean aphid does not typically appear on soybean in Nebraska until late June to mid-July, unlike in other states that tend to see the soybean aphid on soybean as early as the beginning of June. Thus, the soybean aphid is not usually found in Nebraska until soybean are in their reproductive stages, and little is known about soybean resistance to the soybean aphid during this stage of development (Hill et al. 2004, Brosius et al. 2007). The objectives of this research were to identify reproductive stage soybean with resistance to A. glycines and to document the presence of antibiosis and tolerance as categories of resistance to the soybean aphid.

\section{Materials and Methods}

Screening Studies. Six soybean genotypes were evaluated for resistance to the soybean aphid in two replicated studies under greenhouse conditions. The selected genotypes evaluated were as follows: Dowl- ing (MG VIII, reported to have resistance in the seedling stage), Jackson (MG VII, reported to have resistance in the seedling stage), K1621 (MG IV, reported to have resistance in the seedling stage), K-1639-2 (MG V, reported to have resistance in the seedling stage), KS4202 (MG IV, reported to be susceptible in the seedling stage), and 'Asgrow 2703' (MG II, resistance unknown, commercial variety commonly grown in northeastern Nebraska) (Hill et al. 2004, Diaz-Montano et al. 2006).

The experimental design used for both studies was a completely randomized design with six replications. Five genotypes (Dowling, Jackson, K1621, KS4202, and K-1639-2) were used in the first study and six genotypes (Dowling, Jackson, K1621, KS4202, K-1639-2, and Asgrow 2703) were used in the second study. Four seeds of each genotype were planted in potting media ( $34 \%$ peat, $31 \%$ perlite, $31 \%$ vermiculite, and $4 \%$ soil mix) in $15-\mathrm{cm}$-diameter round plastic pots. Plants were thinned to one plant per pot once seedlings emerged from the soil. Soybean was grown to the R2 stage in a greenhouse under 400-W high-intensity lamps, $23 \pm 3^{\circ} \mathrm{C}$, and a photoperiod of 16:8 (L:D) h. Planting dates were adjusted for the different maturity groups to ensure that all plants reached the $\mathrm{R} 2$ stage at approximately the same time.

R2 stage soybean plants were infested with 10 apterous aphids per plant in the first study and 20 apterous aphids per plant in the second study. Soybean aphids were obtained from a laboratory-maintained colony. The original soybean aphid laboratory colony was initiated in July 2005 from individuals collected from infested fields near the University of Nebraska Northeast Research and Extension Center Haskell Agricultural Laboratory (Dixon Co., NE). The colony was maintained on a continuous supply of 'Syngenta S23Z3’ soybean seedlings (V4-V6 stages). New plants were provided weekly to the colony and aphids were transferred by placing infested leaves on new plant leaves. The colony was maintained at $25 \pm 2{ }^{\circ} \mathrm{C}, 75 \pm$ $5 \% \mathrm{RH}$, and a photoperiod of 16:8 (L:D) h in a plant growth chamber. New soybean aphids were introduced into the laboratory colony from the field once per year.

Damage ratings were performed on the experimental soybeans every $4 \mathrm{~d}$ by using a $1-5$ scale, where 1 is $\leq 10 \%$ yellowing discoloration, leaf distortion, plant stunting, and desiccation; 2 is $11-30 \%$ yellowing discoloration, leaf distortion, plant stunting, and desiccation; 3 is $31-50 \%$ yellowing discoloration, leaf distortion, plant stunting, and desiccation; 4 is $51-75 \%$ yellowing discoloration, leaf distortion, plant stunting, and desiccation; and 5 is $\geq 76 \%$ of leaf area with yellowing discoloration, leaf distortion, plant stunting, desiccation, or dead tissue. The scale was a modification of the damage scales reported by Heng-Moss et al. (2002) and Hill et al. (2004) to better characterize injury on reproductive stage soybean. Based on damage rating, genotypes were grouped into one of the four levels of resistance: HS, highly susceptible (damage rating $\geq 4$ ); MS, moderately susceptible (damage rating $\geq 3$ but $<4$ ); MR, moderately resistant (damage 
rating $>1$ but $<3$ ); and $\mathrm{HR}$, highly resistant (damage rating $=1$ ) (Heng-Moss et al. 2002).

Statistical Analyses. Analysis of variance (ANOVA) was conducted for aphid damage ratings and aphid numbers (SAS Institute 2002). Mean separation procedures were conducted when F-tests were significant $(P \leq 0.05)$ by using Fisher least significant difference (LSD) procedures.

Category Study. A category study was conducted to document the presence of antibiosis and tolerance in the resistant genotypes in the screening study. For both the antibiosis and tolerance evaluations, Asgrow 2703 was used as a check because it is a commercial variety commonly grown in northeast Nebraska and is often used for soybean aphid studies (T.E.H., personal communication).

Seeds of the three soybean genotypes K-1639-2, Asgrow 2703, and KS4202 were planted in 15-cmdiameter round plastic pots as described previously in the screening studies. Soybeans were grown to late vegetative or R1 stages in a greenhouse under 400-W high-intensity lamps, $23 \pm 3^{\circ} \mathrm{C}$, and a photoperiod of 16:8 (L:D) h.

A randomized complete block design was used with a 3 by 2 by five factorial treatment design that included three soybean genotypes, two aphid infestation levels ( 0 and 20 soybean aphids), five evaluation dates $(8,14$, 21, 29, and $35 \mathrm{~d}$ after aphid introduction), and 10 replications. Soybean plants were randomly assigned an aphid infestation level. At the start of the experiment, 20 apterous aphids were placed on the youngest fully expanded leaflets of the soybeans designated to be infested. The aphids used in this experiment had been preconditioned by rearing them on soybean in the reproductive stages of each respective genotype (Smith 2005). At the start of the experiment, aphids were introduced onto the same genotype that they were preconditioned on. Aphids were confined to individual plants using tubular 0.08-cm clear Makrolon Tuffak Lexan polycarbonate plastic cages $(15 \mathrm{~cm}$ in diameter by $61 \mathrm{~cm}$ in height) with organdy fabric secured by rubber bands at the top. Soybean with zero aphids was caged as well. The cohort of apterous aphids initially placed on the designated infested plants was removed $48 \mathrm{~h}$ after introduction.

Tolerance Evaluation. A no-choice category study evaluating plant damage and yield parameters between control and aphid-infested plants of the same genotype was conducted to determine the relative levels of tolerance among the genotypes. Infested genotypes having plant damage ratings and yield parameters similar to their respective control plants were designated as tolerant (Smith 2005).

Once per week, aphids were counted and damage ratings were performed using the 1-5 damage scale discussed previously in the screening studies. Damage ratings were taken from both control and aphid-infested plants during each evaluation date. Plant stage also was recorded to test whether aphid feeding had any effect on soybean development.

To further assess the level of tolerance, soybean were harvested 90-145 d after aphid infestation (de-
Table 1. Mean $\pm \mathrm{SE}$ damage ratings and mean number of aphids among the genotypes for screening study 1 at $34 \mathrm{~d}$ after initial infestation of 10 aphids

\begin{tabular}{lcrc}
\hline Genotype & $\begin{array}{c}\text { Mean damage } \\
\text { rating }^{a}\end{array}$ & $\begin{array}{c}\text { Mean no. } \\
\text { aphids }^{b}\end{array}$ & $\begin{array}{c}\text { Resistance }^{b} \\
\text { level }^{c}\end{array}$ \\
\hline Jackson & $3.5 \pm 0.4 \mathrm{a}$ & $180.2 \pm 37.6 \mathrm{~b}$ & MS \\
Dowling & $3.3 \pm 0.3 \mathrm{a}$ & $115.3 \pm 21.2 \mathrm{~b}$ & MS \\
K-1639-2 & $2.7 \pm 0.3 \mathrm{ab}$ & $82.3 \pm 24.6 \mathrm{~b}$ & MR \\
K1621 & $2.7 \pm 0.2 \mathrm{ab}$ & $127.2 \pm 14.8 \mathrm{~b}$ & MR \\
KS4202 & $2.2 \pm 0.2 \mathrm{~b}$ & $380.3 \pm 72.5 \mathrm{a}$ & MR \\
\hline
\end{tabular}

Means within columns followed by the same letter are not significantly different $(P>0.05$; LSD test).

${ }^{a} F_{\text {value }}=3.1 ; \mathrm{df}=4,25 ; P=0.03 ;$ damage rating at $34 \mathrm{~d}$ after aphid introduction.

${ }^{b} F$ value $=8.9 ; \mathrm{df}=4,25 ; P=0.0001$.

${ }^{c} \mathrm{MR}$, moderately resistant; and MS, moderately susceptible.

pending on when plants dried down), and the following yield components were evaluated: number of pods per plant, number of seeds per pod, average seed weight, average dry weight of pod, dry weight of stem, and total plant biomass.

Antibiosis Evaluation. The same plants used in the tolerance evaluation also were assessed for antibiosis. To test for the presence of antibiosis, apterous aphids were introduced and confined to individual plants using tubular cages (as described above), and nymphs were counted $8 \mathrm{~d}$ after aphid infestation to evaluate the plants' effects on aphid multiplicationt. After the initial $8 \mathrm{~d}$, aphids were counted once per week for $35 \mathrm{~d}$ to evaluate the plants' effects on aphid multiplication over time.

Statistical Analyses. Damage ratings, aphid numbers, and yield components were analyzed by mixed model analysis (PROC MIXED, SAS Institute 2002). Block was assigned as the random effect. Mean separation procedures were conducted when $\mathrm{F}$ tests were significant $(P \leq 0.05)$ using Fisher LSD procedures.

\section{Results and Discussion}

Screening Studies. Significant differences in aphid damage ratings were detected among the soybeans evaluated in the screening studies at $34 \mathrm{~d}$ after aphid introduction (study $1: F=3.1$; $\mathrm{df}=4,25 ; P=0.03$; study $2: F=50.9 ; \mathrm{df}=5,30 ; P=0.0001$ ) (Tables 1 and $2)$. The relative ranking of the genotypes was similar between the screening studies; however, infestation levels tended to be higher for study 2 , which resulted in increased damage ratings. Significant differences also were detected in soybean aphid numbers in both studies (study $1: F=8.9$; df $=4,25 ; P=0.0001$; study 2: $F=11.4$; df $=5,30 ; P=0.0001$ ) (Tables 1 and 2). KS4202, K1621, K-1639-2 were identified as moderately resistant, whereas Jackson, Dowling and Asgrow 2703 were moderately to highly susceptible (Tables 1 and 2). Although KS4202 had the highest number of aphids in both studies, it had the lowest damage rating, suggesting possible tolerance. K-1639-2 and K1621, however, had relatively low aphid numbers and damage ratings, indicating antibiosis. 
Table 2. Mean $\pm \mathrm{SE}$ damage ratings and mean number of aphids among the genotypes for screening study 2 at $34 \mathrm{~d}$ after initial infestation of 20 aphids

\begin{tabular}{|c|c|c|c|}
\hline Genotype & $\begin{array}{l}\text { Mean damage } \\
\text { rating }^{a}\end{array}$ & $\begin{array}{l}\text { Mean no. } \\
\text { aphids }^{b}\end{array}$ & $\begin{array}{c}\text { Resistance } \\
\text { level }^{c}\end{array}$ \\
\hline Dowling & $5.0 \mathrm{a}$ & $150.7 \pm 25.2 b$ & HS \\
\hline Asgrow 2703 & $4.8 \pm 0.2 \mathrm{a}$ & $77.2 \pm 39.1 \mathrm{~b}$ & HS \\
\hline Jackson & $3.8 \pm 0.2 \mathrm{~b}$ & $391.0 \pm 41.9 \mathrm{a}$ & MS \\
\hline K1621 & $2.8 \pm 0.2 \mathrm{c}$ & $106.3 \pm 18.1 b$ & MR \\
\hline K-1639-2 & $2.3 \pm 0.2 \mathrm{~d}$ & $102.7 \pm 23.9 b$ & MR \\
\hline KS4202 & $2.3 \pm 0.2 \mathrm{~d}$ & $447.8 \pm 95.7 \mathrm{a}$ & MR \\
\hline
\end{tabular}

Means within columns followed by the same letter are not significantly different $(P>0.05$; LSD test $)$.

${ }^{a} F_{\text {value }}=50.9 ; \mathrm{df}=5,30 ; P=0.0001 ;$ damage rating $34 \mathrm{~d}$ after aphid introduction.

${ }^{b} F$ value $=11.4 ; \mathrm{df}=5,30 ; P=0.0001$

${ }^{c} \mathrm{MR}$, moderately resistant; MS, moderately susceptible; and HS, highly susceptible.

The results from the two greenhouse screening studies suggest the level of resistance may be dependent on the age of the plant. For example, KS4202 has been reported to be susceptible to soybean aphids in the seedling stage (Diaz-Montano et al. 2006, 2007a,b), but this study shows that this same genotype may have increased levels of resistance in the reproductive stages. Jackson and Dowling were found to be moderately susceptible in the reproductive stages; however, they have been reported previously to be resistant in the seedling (Hill et al. 2004, Diaz-Montano et al. 2006) and reproductive stages (Hill et al. 2004). K-1639-2 was reported to be highly resistant in the seedling stage, and our results indicate at least a moderate level of resistance in the reproductive stages. K1621 was reported to have an intermediate (or moderate) level of resistance in the seedling stage, and our results also indicated this level of resistance in the reproductive stages.

Tolerance Evaluation. There were no significant differences in plant stage between the infested and control plants for any of the genotypes on any date (data not shown). The lack of significant differences in plant stage among the genotypes suggests that aphid feeding had no impact on soybean development for the three genotypes at the observed aphid densities.

There was a significant genotype $\mathrm{x}$ infestation level interaction in the analysis of damage ratings $(F=8.5$; $\mathrm{df}=2,198 ; P=0.0003)$. Across all four evaluation dates between 8 and $29 \mathrm{~d}$ after infestation, Asgrow
$2703 \mathrm{had}$ a higher average damage rating in the aphidinfested plants $(2.9 \pm 0.1)$ compared with the noninfested plants $(2.2 \pm 0.1)(P<0.0001)$. The interaction effects of mean damage ratings of the K-1639-2 infested plants $(2.5 \pm 0.1)$ compared with the noninfested plants $(2.5 \pm 0.1)$ and KS4202 infested plants $(2.0 \pm 0.1)$ compared with the noninfested plants $(1.9 \pm 0.1)$ were not significantly different $(P=0.6$ for each). At evaluation dates $14 \mathrm{~d}$ after infestation and longer, simple effects of damage ratings were significantly different between infested and noninfested plants of Asgrow 2703 but not significantly different between infested and noninfested plants of K-1639-2 or KS4202 (Table 3). The lack of visible plant damage on KS4202, despite the large number of aphids, suggests that this soybean genotype possesses some level of tolerance to A. glycines (Fig. 1).

Although there were no significant differences in visible plant damage between control and aphid-infested KS4202 plants, significant differences in biomass $(P=0.01)$, total seed weight $(P=0.02)$, number of pods per plant $(P=0.02)$, and number of seeds per plant $(P=0.04)$ were detected. Aphid-infested KS4202 plants showed a 37,35, and 37\% reduction in the number of seeds per plant, number of pods per plant, and total seed weight compared with KS4202 control plants, respectively. The significant differences in these yield parameters for KS4202 was probably due to the large number of aphids on this genotype. KS4202 consistently had up to 10 -fold the aphid numbers compared with Asgrow 2703 and K-1639-2, and it was the only genotype evaluated that reached the economic threshold level.

No significant differences in average seed weight $(P=0.96)$ or number of seeds per pod $(P=0.39)$ were observed between the infested and control KS4202 plants (Table 4). These findings are consistent with results from field evaluations conducted by Pierson (2009) and suggest that aphid-infested KS4202 plants are producing fewer seeds, but the average individual seed weight is similar to control plants.

There were no significant differences in any of the yield parameters for K-1639-2 or Asgrow 2703 between the infested and control plants (Table 4). The lack of differences in yield parameters for K-1639-2 and Asgrow 2703 is probably due to the low levels of aphids on these two genotypes.

Table 3. Mean \pm SE damage ratings for soybeans for duration of experiment (8-29 d after aphid infestation) in tolerance study

\begin{tabular}{|c|c|c|c|c|c|c|}
\hline \multirow{2}{*}{ Genotype } & \multicolumn{3}{|c|}{$8 \mathrm{~d}$ after aphid introduction } & \multicolumn{3}{|c|}{$14 \mathrm{~d}$ after aphid introduction } \\
\hline & Aphid & Control & $P$ value & Aphid & Control & $P$ value \\
\hline Asgrow 2703 & 2.4 & 2.0 & 0.1435 & 2.9 & 2.1 & 0.0037 \\
\hline K-1639-2 & 2.0 & 2.0 & 1.0000 & 2.7 & 2.3 & 0.1435 \\
\hline \multirow[t]{2}{*}{ KS4202 } & 1.7 & 1.7 & 0.9053 & 2.0 & 1.7 & 0.2849 \\
\hline & \multicolumn{3}{|c|}{$21 \mathrm{~d}$ after aphid introduction } & \multicolumn{3}{|c|}{$29 \mathrm{~d}$ after aphid introduction } \\
\hline Asgrow 2703 & 3.3 & 2.5 & 0.0053 & 3.0 & 2.2 & 0.0120 \\
\hline K-1639-2 & 2.7 & 3.1 & 0.1435 & 2.4 & 2.7 & 0.2720 \\
\hline KS4202 & 2.1 & 2.1 & 0.9626 & 2.0 & 2.0 & 1.0000 \\
\hline
\end{tabular}

Means were compared at a significance level of $P<0.05$ (LSD test); all SEs are 0.2. 


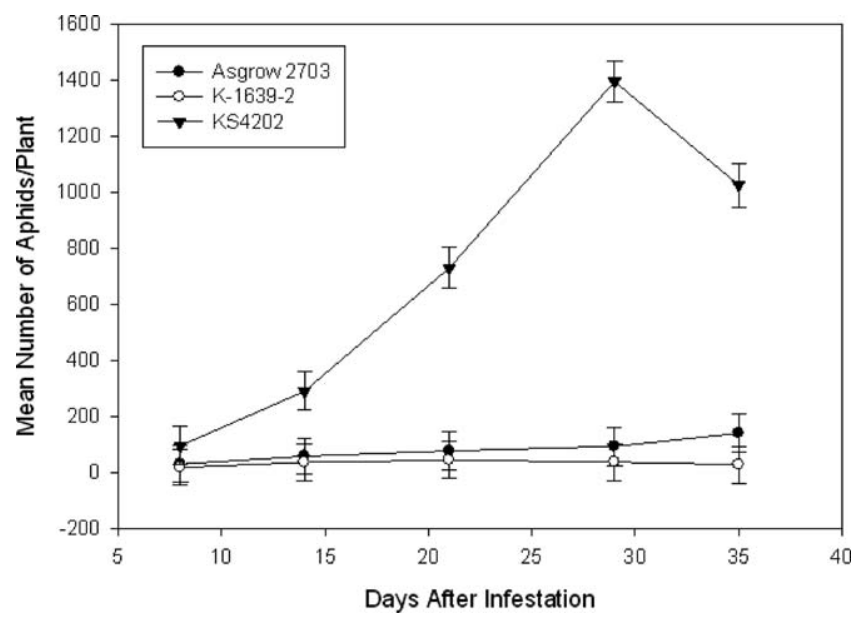

Fig. 1. Mean $\pm \mathrm{SE}$ aphid numbers per plant from 8 to $35 \mathrm{~d}$ after initial infestation of six adult aphids (antibiosis study).

In a study evaluating the impact of soybean aphid feeding on soybean, Beckendorf et al. (2008) found that the soybean aphid significantly reduced the number of pods per plant, seeds per pod, and individual seed weight, all of which contributed to a reduction in overall seed weight per plant in 'Pioneer 91B91' soybean. Not all of these yield components were significantly impacted in KS4202 plants, even at high aphid numbers, suggesting that this genotype possesses some level of tolerance.

Diaz-Montano et al. (2007b) measured chlorophyll loss caused by soybean aphid on soybean, and although there were no significant reductions at $10 \mathrm{~d}$ between plants infested with 30 aphids and unifested plants of genotypes reported previously as resistant (K1621, K1639, Pioneer 95B97, Dowling, and Jackson; Diaz-Montano et al. 2006), the entries were not categorized as tolerant because aphid numbers were too low. In this study, KS4202 was used as the susceptible check because it supported large numbers of aphids, suggesting susceptibility in terms of lack of antibiosis. Further studies are needed to determine whether KS4202 possesses tolerance in the seedling stage.
Antibiosis Evaluation. Nymphs were counted 8 d after infestation, and there were significant differences in aphid numbers among the genotypes $(F=6.1$, df $=2.26, P=0.0067$ ) (Table 3). KS4202 had a significantly higher number of nymphs than Asgrow 2703 $(P=0.01)$ and K-1639-2 $(P=0.003)$. In fact, KS4202 had a threefold difference in the number of nymphs compared with Asgrow $2703(81.8 \pm 14.7$ and $26.2 \pm$ 13.9 nymphs, respectively) and a fivefold difference compared with K-1639-2 (15.6 \pm 13.9$)$ (Table 3). Although not significant $(P=0.59)$, Asgrow 2703 did have more nymphs than K-1639-2, suggesting that K-1639-2 had adverse effects on aphid development that were as strong or stronger than the check commonly used in fields in northeast Nebraska (Asgrow 2703). These results are similar to a study done by Diaz-Montano et al. (2006) in which K1639 had significantly fewer aphids than KS4202 during the seedling stage of development. The lower in aphid numbers on infested K-1639-2 plants compared with aphid numbers on Asgrow 2703 and KS4202 plants indicates antibiosis for this genotype. It is also evident from this study and studies by Diaz-Montano et al. (2006, 2007a)

Table 4. Mean \pm SE yield parameters for soybean aphid-infested and non-infested soybean plants grown in the greenhouse (tolerance study)

\begin{tabular}{|c|c|c|c|c|c|c|}
\hline \multirow{2}{*}{ Genotype } & \multicolumn{3}{|c|}{ Total plant biomass (g) } & \multicolumn{3}{|c|}{ Avg. seed wt (g) } \\
\hline & Aphid & Control & $P$ value & Aphid & Control & $P$ value \\
\hline Asgrow 2703 & $2.7 \pm 0.3$ & $3.3 \pm 0.3$ & 0.1635 & $0.124 \pm 0.014$ & $0.153 \pm 0.015$ & 0.1742 \\
\hline K-1639-2 & $7.6 \pm 0.6$ & $9.1 \pm 0.7$ & 0.1338 & $0.130 \pm 0.005$ & $0.130 \pm 0.005$ & 0.9592 \\
\hline KS4202 & \multicolumn{3}{|c|}{ No. seeds per plant } & \multicolumn{3}{|c|}{ No. pods per plant } \\
\hline Asgrow 2703 & $11.0 \pm 1.4$ & $12.7 \pm 1.5$ & 0.4219 & $6.1 \pm 0.8$ & $6.3 \pm 0.8$ & 0.9273 \\
\hline K-1639-2 & $28.2 \pm 2.3$ & $33.1 \pm 2.6$ & 0.1793 & $16.8 \pm 1.6$ & $18.9 \pm 1.8$ & 0.3902 \\
\hline KS4202 & $19.9 \pm 2.1$ & $31.7 \pm 3.2$ & 0.0158 & $13.0 \pm 1.6$ & $20.0 \pm 2.5$ & 0.0438 \\
\hline & \multicolumn{3}{|c|}{ Total seed wt per plant } & \multicolumn{3}{|c|}{ Avg. no. seeds per pod } \\
\hline Asgrow 2703 & $1.33 \pm 0.16$ & $1.83 \pm 0.17$ & 0.0562 & $1.82 \pm 0.14$ & $1.91 \pm 0.15$ & 0.6453 \\
\hline K-1639-2 & $3.63 \pm 0.30$ & $4.26 \pm 0.34$ & 0.1834 & $1.67 \pm 0.07$ & $1.77 \pm 0.07$ & 0.3500 \\
\hline KS4202 & $2.55 \pm 0.27$ & $4.01 \pm 0.41$ & 0.0178 & $1.54 \pm 0.04$ & $1.61 \pm 0.06$ & 0.3927 \\
\hline
\end{tabular}

Means were compared at a significance level of $P<0.05$ (LSD test). 
that KS4202 does not possess antibiosis during any stage of soybean development.

Total aphid number over time was also evaluated to gain a better understanding of aphid pressure on each genotype. There was a significant genotype $\mathrm{x}$ day interaction $(F=18.2 ; \mathrm{df}=8,123 ; P<0.0001)$. At $8 \mathrm{~d}$ after infestation, KS4202 did not have significantly different aphid numbers/plant from Asgrow $2703(P=0.49)$ or K-1639-2 $(P=0.42)$, nor were aphid numbers between Asgrow 2703 and K-1639-2 significantly different $(P=$ 0.90) (Fig. 1). However, by $14 \mathrm{~d}$ after infestation, KS4202 had significantly higher aphid numbers than Asgrow $2703(P=0.02)$ and K-1639-2 $(P=0.008)$, and aphid numbers remained significantly higher throughout the experiment (Fig. 1). In fact, by $21 \mathrm{~d}$ after infestation, KS4202 had nearly a 10-fold difference in aphid numbers compared with Asgrow 2703; and because of the high numbers in KS4202, it was difficult to detect differences between Asgrow 2703 and K-1639-2 (Fig. 1). Because of this, KS4202 was removed from the analysis and differences between Asgrow 2703 and K-1639-2 were calculated again. There was a significant genotype $\times$ day interaction $(F=3.30$; $\mathrm{df}=4,87 ; P=0.01)$. Asgrow 2703 aphid numbers increased significantly from 8 to $35 \mathrm{~d}$ after infestation $(P<0.0001)$, whereas numbers on $\mathrm{K}-1639-2$ remained stable during that same period of time $(P=0.65)$. Differences in average aphid numbers between Asgrow 2703 and K-1639-2 appeared at 29 and $35 \mathrm{~d}$ after infestation $(P=0.01$ and $P<0.0001$, respectively), indicating that the number of aphids on Asgrow 2703 continued to rise significantly over time even as the number of aphids on K-1639-2 remained stable.

Because much of the literature involving resistance to the soybean aphid focuses on the seedling stages of soybean plants, most studies only look at the number of aphids per plant not long after aphid introduction to study the immediate impacts. However, because the soybean aphid does not typically infest Nebraska soybean until their late vegetative or early reproductive stages, and because soybean plants in these stages are usually able to survive initial aphid infestation, it was important to examine aphid numbers over time. In this study, initial aphid numbers were relatively similar between K-1639-2 and Asgrow 2703, but at later evaluation dates, K-1639-2 had lower aphid numbers than Asgrow 2703, indicating antibiosis during the reproductive stages for K-1639-2.

The results from this research on categorizing the resistance of KS4202 and K-1639-2 support the findings of Diaz-Montano et al. (2006, 2007a) and Pierson (2009). This research represents the first report of antibiosis in the reproductive stages of K-1639-2 and suggests KS4202 possesses some level of tolerance. Although some of the yield parameters were significantly different between the control and aphid-infested KS4202 plants at extremely high aphid levels, average seed weight, number of seeds per pod, and plant damage were similar between control and aphid infested plants. Based on these findings, KS4202 seems to tolerate aphid feeding to some degree because average seed weight and number of seeds per pod were not impacted. Future studies should focus on further characterization of the tolerance response in KS4202 and gaining a better understanding of the compensation mechanisms exhibited by KS4202 in response to aphid feeding.

\section{Acknowledgments}

We acknowledge Mitchell Stamm, Sandra Schaeffer, and Travis Prochaska for technical assistance; Erin Blankenship for statistical assistance; and William T. Schapaugh, Jr., for providing the soybean germplasm for these studies. This research was supported in part by the University of Nebraska Agricultural Experiment Station Projects NEB-28-097 and NEB-41-034 and the North Central Soybean Research Program.

\section{References Cited}

Alleman, R. J., C. R. Grau, and D. B. Hogg. 2002. Soybean aphid host range and virus transmission efficiency. In Proceedings of the Wisconsin Fertilizer, Agline Pest Management Conference. (http://www.soils.wisc.edu/ extension/FAPM/2002proceedings/Alleman-Conf-2002. pdf).

Beckendorf, E. A., M. A. Catangui, and W. E. Riedell. 2008. Soybean aphid feeding injury and soybean yield, yield components, and seed composition. Agron. J. 100: 237246.

Brosius, T. R., L. G. Higley, and T. E. Hunt. 2007. Population dynamics of soybean aphid and biotic mortality at the edge of its range. J. Econ. Entomol. 100: 1268-1275.

Chacón, J. M., D. A. Landis, and G. E. Heimpel. 2008. Potential for biotic interference of a classical biological control agent of the soybean aphid. Biol. Control 46: 216-225.

Clark, A. J., and K. L. Perry. 2002. Transmissibility of field isolates of soybean viruses by Aphis glycines. Plant Dis. 86: $1219-1222$

Davis, J. A., E. B. Radcliffe, and D. W. Ragsdale. 2005. Soybean aphid, Aphis glycines Matsumura, a new vector of Potato virus $Y$ in potato. A. J. Potato Res. 82: 197-201.

Desneux, N., R. J. O’Neil, and H.J.S. Yoo. 2006. Suppression of population growth of the soybean aphid, Aphis glycines Matsumura, by predators: the identification of a key predator and the effects of prey dispersion, predator abundance, and temperature. Environ. Entomol. 35: 13421349.

Diaz-Montano, J., J. C. Reese, J. Louis, L. R. Campbell, and W. T. Schapaugh. 2007a. Feeding behavior by the soybean aphid (Hemiptera: Aphididae) on resistant and susceptible soybean genotypes. J. Econ. Entomol. 100: $984-$ 989 .

Diaz-Montano, J., J. C. Reese, W. T. Schapaugh, and L. R. Campbell. 2006. Characterization of antibiosis and antixenosis to the soybean aphid (Hemiptera: Aphididae) in several soybean genotypes. J. Econ. Entomol. 99: 18841889.

Diaz-Montano, J., J. C. Reese, W. T. Schapaugh, and L. R. Campbell. 2007b. Chlorophyll loss caused by soybean aphid (Hemiptera: Aphididae) feeding on soybean. J. Econ. Entomol. 100: 1657-1662.

DiFonzo, C. 2008. Soybean aphid biological control-an ongoing NCRSP project. Plant Health Initiative. (http:// www.planthealth.info/aphids_biocontrol_update.htm).

Domier, L. L., I. J. Latorre, T. A. Steinlage, N. McCoppin, and G. L. Hartman. 2003. Variability and transmission by 
Aphis glycines of North American and Asian Soybean mosaic virus isolates. Arch. Virol. 148: 1925-1941.

Fox, T. B., D. A. Landis, F. F. Cardoso, and C. D. Difonzo. 2004. Predators suppress Aphis glycines Matsumura population growth in soybean. Environ. Entomol. 33: 608618.

Fox, T. B., D. A. Landis, F. F. Cardoso, and C. D. Difonzo. 2005. Impact of predation on establishment of the soybean aphid, Aphis glycines in soybean, Glycine max. Biocontrol 50: 545-563.

Hartman, G. L., L. L. Domier, L. M. Wax, C. G. Helm, D. W. Onstad, J. T. Shaw, L. F. Solter, D. J. Voegtlin, C. J. D'Arcy, M. E. Gray, et al. 2001. Occurrence and distribution of Aphis glycines on soybeans in Illinois in 2000 and its potential control. (http://planthealthprogress.org/ current/briefs/aphisglycines/article.htm).

Heimpel, G. E., D. W. Ragsdale, R. Venette, K. R. Hopper, R. J. O’Neil, C. E. Rutledge, and Z. Wu. 2004. Prospects for importation biological control of the soybean aphid: anticipating potential costs and benefits. Ann. Entomol. Soc. Am. 97: 249-258.

Heng-Moss, T. M., F. P. Baxendale, T. P. Riordan, and J. E. Foster. 2002. Evaluation of buffalograss germplasm for resistance to Blissus occiduus (Hemiptera: Lygaeidae). J. Econ. Entomol. 95: 1054-1058.

Hill, C. B., Y. Li, and G. L. Hartman. 2004. Resistance to the soybean aphid in soybean germplasm. Crop Sci. 44: $98-$ 106.

Hill, C. B., Y. Li, and G. L. Hartman. 2006a. A single dominant gene for resistance to the soybean aphid in the soybean cultivar Dowling. Crop Sci. 46: 1601-1605.

Hill, C. B., Y. Li, and G. L. Hartman. 2006b. Soybean aphid resistance in soybean Jackson is controlled by a single dominant gene. Crop Sci. 46: 1606-1608.

Kaiser, M. E., T. Noma, M. J. Brewer, K. S. Pike, J. R. Vockeroth, and S. D. Gaimari. 2007. Hymenopteran parasitoids and dipteran predators found using soybean aphid after its midwestern United States invasion. Ann. Entomol. Soc. Am. 100: 196-205.

Kang, S. T., M.A.R. Mian, and R. B. Hammond. 2008. Soybean aphid resistance in PI 243540 is controlled by a single dominant gene. Crop Sci. 48: 1744-1748.
Kim, K. S., C. B. Hill, G. L. Hartman, M.A.R. Mian, and B. W. Diers. 2008. Discovery of soybean aphid biotypes. Crop Sci. 48: 923-928.

Mian, M.A.R., R. B. Hammond, and S. K. St. Martin. 2008. New plant introductions with resistance to the soybean aphid. Crop Sci. 48: 1055-1061.

Mensah, C., C. DiFonzo, R. L. Nelson, and D. Wang. 2005. Resistance to soybean aphid in early maturing soybean germplasm. Crop Sci. 45: 228-2233.

Pierson, L. M. 2009. Resistance to Aphis glycines Matsumura during the reproductive stages of soybeans. M.S. thesis, University of Nebraska-Lincoln, Lincoln, NE.

Rutledge, C. E., and R. J. O'Neil. 2005. Orius insidiosus (Say) as a predator of the soybean aphid, Aphis glycines Matsumura. Biol. Control 33: 56-64.

Rutledge, C. E., R. J. O’Neil, T. B. Fox, and D. A. Landis. 2004. Soybean aphid predators and their use in integrated pest management. Ann. Entomol. Soc. Am. 97: $240-248$.

SAS Institute. 2002. PROC user's manual, version 9.1. SAS Institute, Cary, NC.

Smith, C. M. 2005. Plant resistance to arthropods. Springer, Dordrecht, The Netherlands.

Venette, R. C., and D. W. Ragsdale. 2004. Assessing the invasion by soybean aphid (Homoptera: Aphididae): where will it end? Ann. Entomol. Soc. Am. 97: 219-226.

Wang, Y. Z., and F. Ba. 1998. Study on optimum control of the soybean aphid. Acta Phyt. Sin. 25: 152-155.

Wang, Y. Z., L. Ma, J. Z. Wang, X. Z. Ren, and W. L. Zhu. 2000. Systematic optimum control of diseases and insect pests in summer soybean. J. Ecol. 20: 502-509.

Wu, Z., D. Schenk-Hamlin, W. Zhan, D. W. Ragsdale, and G. E. Heimpel. 2004. The soybean aphid in China: a historical review. Ann. Entomol. Soc. Am. 97: 209-218.

Wyckhuys, K.A.G., L. Stone, N. Desneux, K. A. Hoelmer, K. R. Hopper, and G. E. Heimpel. 2008. Parasitism of the soybean aphid, Aphis glycines by Binodoxys communis: the role of aphid defensive behaviour and parasitoid reproductive performance. Bull. Entomol. Res. 98: 361-370.

Received 1 October 2009; accepted 2 April 2010. 